\title{
Supervivencia de los objetos de rango prehispánicos entre la nobleza colonial nahua
}

\author{
Justyna Olko \\ Instituto de Estudios Interdisciplinarios «Artes Liberales» \\ Universidad de Varsovia \\ jolko@ibi.uw.edu.pl
}

Recibido: 18 de enero de 2011

Aceptado: 14 de febrero de 2011

\begin{abstract}
RESUMEN
A pesar de la amplia adopción de la indumentaria europea y de los esfuerzos de la nobleza indígena para conseguir los atributos de rango foráneos, hay evidencias de la persistencia del traje e insignias prehispánicas en la realidad colonial temprana. El artículo explora los datos disponibles sobre la supervivencia de estos símbolos de rango -incluyendo tanto los objetos heredados como los manufacturados en la época colonial según los prototipos precolombinos - centrándose en los contextos de su uso. Una parte importante de este fenómeno se asocia a la pervivencia de la propia terminología precolonial relacionada con los objetos de prestigio, que coincide con la pervivencia de los títulos tradicionales referidos a la nobleza, adaptándose esta última a las nuevas formas de organización sociopolítica.
\end{abstract}

Palabras clave: Nahuas, nobleza, símbolos de rango, insignias, terminología precolonial

\section{Survival of pre-Hispanic Objects of Rank Among Colonial Nahua Nobility}

\begin{abstract}
In spite of the wide adoption of European apparel and attempts of indigenous nobility to gain foreign attributes of rank, there is evidence of the persistence of native dress and insignia in early colonial reality. The paper explores extant data that reveal the survival of pre-Hispanic symbols of rank, including both inherited and contemporarily manufactured objects, and focuses on the contexts of their use. An important part of this phenomenon was the continuation of precontact terminology related to prestigious items, that coincides with the persistence of traditional titles of nobility and offices, which were gradually adapted to new forms of sociopolitical organization.
\end{abstract}

Key words: Nahuas, nobility, symbols of rank, insignia, preconquest terminology.

Aunque el gran conocedor de la cultura indígena, George Kubler, refiriéndose a la supervivencia de la tradición prehispánica en el arte colonial, constató que las continuidades son tan escasas y dispersas que encontrarlas y recopilarlas es «como buscar los fragmentos de un naufragio profundo» (Kubler 1964), las investigaciones de las últimas décadas siguen revelando numerosos elementos y vislumbrando fenómenos de la época precolonial en el siglo XVI y más adelante. Un ámbito particularmente importante de esta continuación es la nobleza indígena que logró conservar gran parte de su posición y prestigio anterior, a la vez que, sin rechazar sus raíces prehispánicas, mantuvo un diálogo con la cultura europea. Una esfera significativa de esta supervivencia es la terminología náhuatl asociada al poder y al rango, que no sólo sobrevivió a la conquista española, sino que llegó a ajustarse a la nueva realidad cultural y política. 
El ámbito de la terminología tradicional incluye tanto los títulos como varios objetos prestigiosos que se empleaban frecuentemente para definir la posición heredada o adquirida. En el frecuente uso de los títulos prehispánicos relativos al poder, en la referencia a los oficios y funciones cumplidas en el sistema administrativo de la Nueva España en el siglo XVI, hay que ver tanto la fuerza de la tradición indígena, como un efecto de la afinidad percibida entre los oficios precoloniales y los cargos españoles. Aunque ya en las primeras décadas después de la conquista se observan ciertas modificaciones del sentido original y de las funciones de varios títulos, hacia fines del siglo XVI y durante el siglo XVII este fenómeno sufre, incluso, unas transformaciones más profundas. Al mismo tiempo en numerosas fuentes puede detectarse la presencia de otros términos prehispánicos relacionados con la nobleza, incluyendo las referencias a los objetos del rango o metáforas asociadas al poder.

Aunque el tema principal de este trabajo son los propios objetos materiales relativos al poder, para comprender este fenómeno vale la pena trazar una perspectiva general acerca del uso de los títulos más significativos de la nobleza colonial novohispana. Son éstos títulos y su uso los que permiten acercarnos a la ubicación de las propias élites entre los dos mundos, prehispánico y europeo, así como entre sus respectivas bases del poder. Al echar una luz importante sobre las posiciones y funciones a las cuales aspiraban los miembros de la élite, ayudan a entender hasta qué punto era posible conservar la tradición prehispánica dentro del sistema municipal y administrativo introducido por los españoles. Uno de los títulos nahuas que muestra gran vigencia en el período colonial es tlatoani, referido en tiempos prehispánicos a los gobernantes dinásticos del altepetl. En las primeras décadas después de la conquista era utilizado de acuerdo con su sentido original, principalmente en referencia a los gobernantes dinásticos; aunque si estos cumplían también la función de gobernador en el cabildo, se los intitulaba como «tlatoani y gobernador».

Sin embargo, ya en la segunda mitad del siglo XVI, se empezó a emplear el título de tlatoani también en relación con todos los gobernadores, incluyendo aquellos que no desempeñaban la función del gobernante dinástico, mientras que el oficio del gobernador adquirió mucho del aura y prestigio del tlatocayotl prehispánico (Lockhart 1992: 30-31; Haskett 1991: 100). En los Anales de Tecamachalco, por ejemplo, en relación al año 1555 se utiliza el término tlatocayotl en referencia al gobernante dinástico, don Juan de Mendoza (titulado directamente tlatoani de Tecamachalco) y su «señorío» (Anales de Tecamachalco pp. 34-35). Es significativo, no obstante, que en la entrada del año 1557 aparece el término tlatoani en referencia al gobernador nominado y suspendido por el virrey (Anales de Tecamachalco pág. 36) lo que confirma la fluidez progresiva de la aplicación de esta palabra y su adaptación a la realidad colonial $^{1}$. Sin embargo, como veremos a continuación, en la evidencia de que dispo-

1 Se usan también otros términos relacionados con la persona y función del tlatoani, que sufren modificaciones parecidas a los del mismo título. Uno de ellos es tlatocaicpalli «el asiento del mando [de tlatoani], trono real» que en los Anales de Tecamachalco aparece en la expresión «contlalcaui yn yeyantli tlahtocaycpalli» («dejó el asiento, el trono real»). Aquí tlatocaicpalli se refiere al reemplazo en el puesto gobernador, y no del propio tlatoani, en el año 1563, aunque esta fuente también utiliza el neologismo gobernadoryotl para remitirse a este oficio (Anales de Tecamachalco pp. 47, 53). 
nemos, la pervivencia de las antiguas insignias se asocia principalmente a los propios tlatoque dinásticos que a la vez cumplen funciones importantes en la organización municipal de sus altepetl y hacen numerosos esfuerzos para conservar y transmitir el poder y oficios dentro de sus linajes gobernantes.

Con el tiempo, el título de tlatoani cambia y amplia su sentido original empezando a funcionar como un título de cortesía. Ya en el siglo XVI su versión plural, tlatoque, se empleaba en referencia a un grupo de funcionarios del cabildo, ninguno de los cuales era un gobernante dinástico (Lockhart 1992: 133). Funcionaba como apelativo de un cuerpo colectivo de representantes de un grupo de autoridad indígena o designaba a oficiales particulares, como los alcaldes referidos como totlatocahuan («nuestros tlatoque») en los Anales de Juan Bautista (fol. 17r) elaborados entre los años sesenta y ochenta del siglo XVI. Como continuación de este fenómeno, en el siglo XVII el título de tlatoani aparece en su forma singular como un apelativo de varios funcionarios, como un fiscal o alcalde, mientras que los usos más tardíos del título de tlatoani como gobernante dinástico en los textos nahuas se remontan a los años sesenta del siglo XVII (Lockhart 1992: 132-133). Al mismo tiempo, se sigue utilizando en referencia a los gobernadores sin base dinástica, como lo confirma el caso del gobernador de Cuernavaca, miembro de una familia mestiza influyente, don Antonio de Hinojosa. Este personaje, probablemente en relación al puesto del gobernador ocupado antes también por su padre, es citado en 1673 como tlatocaconetl, «hijo de tlatoani» (Haskett 1991: 152), cuyo sentido hay que entender más bien como «descendiente real»o «hijo real» ${ }^{2}$.

De modo parecido, los miembros del cabildo gozan de otros títulos de origen prehispánico, como tlatoque, pipiltin, tlatoque altepehuaque, tlaçopipiltin o tlaçotlatoque. Como en el caso de los usos tardíos de tlatoani, hay que ver en ellos más bien las fórmulas políticas que los títulos, con el mismo campo semántico y funcional que en la época precolonial o incluso de las primeras décadas de la colonia. No obstante, aunque ya en la segunda mitad del siglo XVI se observan transformaciones del sentido de varios términos, todavía se pueden notar casos de uso de los antiguos títulos de acuerdo con su función original ${ }^{3}$. El uso «correcto» de esta terminología tradicional se hace más extraordinario en el siglo XVII, cuando aparecen también unas nuevas combinaciones a partir de las palabras tradicionales.

Como se expondrá más adelante, el uso de los objetos de origen prehispánico estaba estrechamente relacionado con el concepto del poder heredado y del patrimonio, lo cual se ve también reflejado en el empleo de la terminología pertinente a esta esfera de la vida colonial. En este contexto, los miembros de la nobleza siguen manejando la importante noción de tlatocayotl, cuyo uso en la época colonial se desplaza de la entidad encabezada por un tlatoani o su oficio a las tierras del cacicazgo. Aunque en un testamento de don Mateo de los Santos (de Quiyahuistlan) de los años 1692-1693

2 El mismo término aparece en el testamento de don Juan Bernardino, fiscal del pueblo de Cempoallan, del año 1608 (VBO III, 93).

3 Por ejemplo los Anales de Juan Bautista mencionan el término prehispánico quauhhuehuetque asociado con el grupo de veteranos militares como participantes de una ceremonia celebrada en un palacio del gobernador (fol. 20r). 
(VBO III: 367) encontramos el termino tlatocayotl en referencia a la cabecera de Quiyahuistlan ${ }^{4}$, de acuerdo con el uso de este término en el siglo XVI (comp. Sullivan 1987: 36), la mayoría de las referencias de esta época parecen aludir específicamente al patrimonio en el sentido de las tierras del cacicazgo ${ }^{5}$.

Ya que tlatocayotl en el periodo colonial está estrechamente asociado con las tierras pertenecientes al linaje gobernante, un término que se emplea frecuentemente es tlatocatlalli. Los investigadores observan que los términos tlatocatlalli, tecpantlalli (tierras pertenecientes al palacio) o teuctlalli (tierras de señores, teteuctin), desaparecen de los documentos nahuas desde los principios del siglo XVII, mientras que pillalli (tierra de los nobles) persiste hasta la segunda mitad de este siglo, volviéndose muy rara su mención en el XVIII (Lockhart 1992: 163, 174-175; Horn 1997: 121). No obstante, se pueden detectar excepciones. En 1680 don Juan Montesinos, cacique de San Andrés Calpan con unas extensas propiedades, no se refiere a si mismo con el título de tlatoani, pero designa sus tierras como tlatocatlalli (VBO III: 313). En su testamento lega las tierras del señorío a sus dos hijos que tienen que «guardarlas siempre porque esta es toda nuestra tlatocatlalli, la cuidarán y estarán a cargo de ella, la desempeñarán ya que no ha sido vendida ${ }^{6}$; esta tierra «no ha sido vendida y tampoco pertenece a otras personas que la guardaban, pero es toda tlatocatlalli $>$. Lo que se desprende de estos testimonios es un valor inmaterial de la tierra asociada con el antiguo oficio de tlatoani que no puede ser dividida o llegar a ser un objeto de venta, ya que sólo puede permanecer como herencia en las manos de sus propios descendientes.

Las mismas categorías de personas que defienden su patrimonio y aseguran la herencia de sus hijos confiesan haber conservado algunos objetos de rango de origen prehispánico, atestiguando a la vez la supervivencia de la propia terminología relativa al poder. Hay que subrayar que el cambio en el vestir de la nobleza indígena hacia las costumbres europeas, sin duda concebidas como prestigiosas, se dio de una manera bastante rápida. Los descendientes de las élites precoloniales hacían considerables esfuerzos para conseguir el derecho a los símbolos de un estatus nuevo-armas españolas y el uso de caballos-prohibidos a los indígenas por las ordenanzas reales (Rojas 2010: 263-268; Olko 2005: 469-474; 2008: 209-210). Los elementos del traje

\footnotetext{
4 «ytech nipouhqui yn tlatocayotl cabesera Quiyahuistlan», o sea «pertenezco al tlatocayotl cabecera de Quiyahuistlan».

5 Por ejemplo doña Ana de Santa Bárbara, cacica principal de Santo Domingo Tepexi de Seda, en su testamento de 1621 quiere asegurar la integridad de su cacicazgo: «y este cacicazgo ya se que no lo puedo dividir para que el señorío (tlatocayotl) siempre aparezca y como nuestros padres y abuelos eran señores y nobles en el altepetl y nuestro linaje (tlacamecayotl) no perecerá» («Auh ynin cazicasgo ye nicmati amo huel nicxexeloz ynpampa cemicac neztiez yn tlatocayo[tl] yhuan yn quenin totahuan tocolhuan teteuhtin pipiltin ocatca ypan altepetl auh yn totlacamecayo amo polihuiz»; VBO III, 121). Además prohíbe la venta de las tierras del tlatocayotl: "Asimismo no se puede vender el cacicazgo, porque yo así lo mando, y si lo vende (el heredero), la venta se revocará y no tendrá valor» («Auh zan no yhui ahuelitiz quinamacaz yn cacicasgo ynpanpa yuh nitlanahuatia auh yn tla quinamacaz moxixitiniz yn be[nta] amo tlen ypatiuh yez»).

6 «ynic semicac quimopielisque canel nohi [nochi] totlatocatlal quimoquitlahuisque ypan tlatosque quiquixtisque ca amo tlanamactli»; VBO III, 315.

7 «ynn amo tlanamacti yn amo no imaxca yn ocsequi tlaca yn oquipiaya ca san mohi tlatocatlalli»; VBO III, 315
} 
español se incorporaron gradualmente en la cultura cotidiana indígena a lo largo del siglo XVI (Lockhart 1992: 199-200), pero por supuesto entre sus primeros usuarios estaban sobre todo los miembros de la nobleza. Esta aceptación del estilo europeo, reflejada por las numerosas licencias concedidas a los nobles indígenas, no se ve muy bien representada en la iconografía de rango que aparece en los manuscritos indígenas del siglo XVI, donde llama la atención la frecuente y difundida estrategia de representar a los gobernantes coloniales como si fueran tlatoque prehispánicos con su indumentaria tradicional. En algunos casos, no obstante, figuran en una manera bastante sincrética, lo que se relaciona sin duda con la usanza vigente en la época. Además, aunque en aquel tiempo los casos de representaciones de los indígenas de alto rango de una manera enteramente española -al menos en los manuscritos pictóricos- son bastante limitados (Olko 2005, 2008), no parece improbable que éstos, en muchos casos, puedan haber reflejado su manera real de vestir.

A pesar de la evidencia de una amplia aceptación de la moda española, se pueden identificar varios datos que sugieren que la nobleza indígena asociaba y confirmaba la supervivencia de su estatus no sólo con los privilegios y revalidación por parte de la corona española, sino también con ciertos atributos prehispánicos. Testimonios del empleo continuo de éstos nos los proporcionan cronistas que participaban de la vida colonial temprana, algunos de los cuales, como por ejemplo don Hernando de Alvarado Tezozomoc, eran miembros de la nobleza indígena. En su relato, al mencionar algunas insignias en su contexto prehispánico, añade un comentario sobre su uso contemporáneo: así los indígenas «traían cargas de plumería <que> llaman el día de oy quetzalpatzactli» (Tezozomoc 2001: 259) o refiriéndose a un asiento real, lo describe como «la silla, $<$ que $>$ hera de un cuero de tiguere, baxo, al uso antiguo y oy se usa <en>tre todos los naturales» (Tezozomoc 2001: 248).

Por otro lado, existen varias pruebas del uso continuo de los objetos antiguos de rango entre la élite indígena gracias a sus testamentos, principalmente los de los siglos XVI y XVII. Esté género de fuentes indígenas no sólo atestigua la posesión de ciertos objetos, sino también su donación a los herederos y, en algunos casos, su continua fabricación. Entre los testadores tenemos a los tlatoque indígenas, teteuctin y gobernadores, en la mayoría de los casos probablemente con la legitimación dinástica a este puesto, o sea los «caciques y gobernadores». La indumentaria antigua gozaba de bastante prestigio en Quauhtinchan cuyos tlatoque coloniales poseían prestigiosos collares con pendientes esparcidos (chayahuac cozcatl), abanicos (ehecacehuaztli), adornos para brazos decorados con plumas ricas (machoncotl), trenzaderas (tlalpiloni) o mantas con diseños de águila y asientos (Reyes García 1988a: 105). Objetos parecidos encontramos en el testamento de don Pedro de San Francisco Tlaquixtecatl, gobernador del pueblo de San Francisco Tlahuililpan, quien en el año 1586 enumera el brazalete machoncotl, tres abanicos de plumas de quetzal (quetzalehecacehuaztli) y tres quetzallamamalli o divisas de plumas de quetzal (VBO II: 265-266). Al mismo tiempo complementa su repertorio de objetos del rango con una nueva silla española («silla yancuic»), lo que atestigua el «diálogo» con los símbolos del rango de ambas culturas, prehispánica y europea. En cuanto a las insignias tradicionales, don Pedro pasa el brazalete así como uno de los abanicos a su hijo don Diego, lo que sugiere 
un estatus hereditario de estos objetos dentro de las familias nobles. Uno de los quetzallamamalli se otorga a los «nobles y plebeyos» para las fiestas (véase la discusión abajo).

Lo mismo ocurre con otro señor notable, don Julián de Rosa, un teuctli, o jefe de la casa señorial (teccalli) de San Pedro Tecpan en Ocotelolco, Tlaxcala (Lockhart s.f.). Este personaje en el año 1566 poseía varias mantas decoradas con diseños de tradición prehispánica (huacalxochiyo tilmatli) y lo que llama la atención, vestimentas de guerra completas, entre ellas un traje de mono cubierto de plumas con una divisa de cabeza de faisán («oçomahtli ytlacayo yuan coxcox ytzontecon»), un traje de guerrero de coyote junto con la divisa con penacho de plumas («coyotl ytzontecon yuan patzactli») y un escudo decorado con 200 plumas de quetzal (Lockhart 1992: 198-199; s. f.). El traje de coyote era bastante común en el repertorio de atuendos militares prehispánicos, tal y como aparece por ejemplo en la Matrícula de Tributos y el Códice Mendoza. El traje de mono, aunque al parecer está ausente en las listas de las insignias prehispánicas contenidas en las fuentes primarias del centro de Méxi$\mathrm{co}^{8}$, aparece varias veces en las festividades descritas en los Anales de Juan Bautista (fols. $19 \mathrm{v}, 40 \mathrm{v}$ ) relativas a acontecimientos acaecidos durante los años sesenta del siglo XVI, es decir, precisamente el momento de elaboración del testamento de don Julián. En los mismos anales aparecen también términos prehispánicos referentes a las insignias militares, como la palabra general tlahuiztli y el tipo específico tlamamalli, mencionado en el testamento don Pedro de San Francisco Tlaquixtecatl arriba discutido, que designaba las insignias llevadas a cuestas. Estas referencias confirman un uso vigente de estos objetos (aunque sea en contextos hasta cierto punto diferentes a los de la época prehispánica), así como de la propia terminología en la segunda mitad del siglo XVI.

Regresando a los vestidos poseídos por don Julián de la Rosa, parece interesante que una de las mantas estaba hecha de las plumas del pato (patosihuitl) lo que demuestra cómo un material ajeno se incorporó en una fabricación tradicionalmente indígena. Uno de los trajes militares iba a permanecer entre los nobles de teccalli, Bautista Cuicuitlapan, probablemente hermano menor y futuro sucesor del testador, y Diego, su primo hermano (al parecer, don Julián no tenía un heredero directo), quienes son también nombrados como personas que se ocuparán juntos de la residencia del teccalli y recibirán servicios de sus dependientes (Lockhart s.f.). Parece significativo que los mismos individuos reciben también los objetos asociados con la nobleza prehispánica.

No obstante, es también destacable que el destino de otras insignias de don Julián de la Rosa fuese bastante distinto. Las plumas del otro traje guerrero tenían que ser sacadas y vendidas para comprar las candelas para la iglesia de San Pedro Tecpan. Del mismo modo, las mantas de nobleza, entre ellas la huacalxochiyo tilmatli y la manta de plumas de pato, iban a ser vendidas para decir misas. Así, a pesar del prestigio de estas insignias, la devoción cristiana resulta ser más importante que la preservación de un objeto de origen, o al menos estilo, prehispánico.

\footnotetext{
8 No obstante, el traje de mono aparece ilustrado en el Códice Dehesa del área mixteca.
} 
Quizás un testimonio más sorprendente en lo que se refiere al grado de la preservación de la conciencia de la tradición prehispánica, sea el testamento de don Miguel Alexandrino, gobernador de Tullantzinco, del año 1577. Probablemente era también un tlatoani y el oficio permanecía en las manos de su linaje, dado que menciona a su padre don Julián de San Francisco, también gobernador y se refiere a su hijo, don Diego Alexandrino como su sucesor llamándole con el propio título de tlatoani (VBO II: 193). Además, en la anotación final al documento (también en nahuatl) su hijo aparece como señor don Diego Alexandrino (VBO II: 199). Se le menciona también en la averiguación del año 1579 hecha para reconocerle como «heredero del cacicazgo y bienes de su padre» (AGN, Tierras 2723, exp. 2).

Entre las posesiones de don Miguel Alexandrino se enumeran dos macopilli o «brazaletes de pluma rica» (Molina, fol. 51r) que manda vender por la considerable cantidad de cuarenta y seis pesos. Hay que subrayar que este adorno figura en las fuentes primarias del siglo XVI como quetzalmacopilli, o sea una banda o ajorca llevada en el brazo acabada con un elemento cónico llamado copilli y decorada con un manojo de plumas de quetzal, atributo real en el baile según los Primeros Memoriales (fol. 56r) o como xiuhmacopilli (el mismo tipo de ajorca pero cubierta con el mosaico de turquesa), un adorno de gobernantes en el baile según el Códice Florentino (Sahagún 1950-82, VIII: 28). Sin lugar a dudas, eran atributos de la realeza prehispánica par excellence. Llama la atención que don Miguel añade que son nuevos, lo que significa que no eran viejos objetos heredados de los antepasados, sino fabricados y utilizados en aquel tiempo según la costumbre prehispánica. Este interesante dato implica además la existencia de talleres indígenas que se dedicaban a la manufactura de los objetos tradicionales.

Asimismo, el testador otorga a su hijo don Diego, como su sucesor principal, lo que llama explícitamente un «atavío real» (tlatocatlatquitl) - «Y el pájaro de quetzal y las cinco piedras verdes que los guarde mi hijo don Diego porque son un atavío real»- el cual debe guardar como el tlatoani obligado a proteger a sus súbditos (VBO II: 191-193)9. Como es bien sabido, la piedra verde tenía mucho prestigio y sentido simbólico antes de la conquista, mientras que el término quetzaltototl se refiere a la divisa militar llevada a cuestas, descrita con ese nombre e ilustrada en los Primeros Memoriales (fols. 68r, 74r), así como ilustrada en el Códice Mendoza (fol. 46r) y Códice de Tlatelolco como insignia de gobernantes y nobles. Además, el término tlatocatlatquitl, «atavío real» o «vestimenta de la realeza», aparece en los Primeros Memoriales (fol. 65r) refiriéndose a las insignias de guerra más prestigiosas. Don Miguel Alexandrino parece usarlo conscientemente de acuerdo con este sentido pre-

\footnotetext{
9 «Auh yn quetzaltohtotl yuan chalchiuitl mahcuiltetl uel vquimopiyaliz yn nopiltzin don Diego yehica ca tlahtocatlatquitl. Auh cenca nicnotlatlauhtilia ypaltzinco yn totecuiyo yn Dios yn tlahtohuani macamo yhca mocacayauaz yn inantzin yuan yn mochintin nopilhuan yhuan noteyccauan yuan nomachua yuan yn ixquichtin ynma yn magnificos señores ma cenca quinmomahuiztililiz yuan calpolleque yniquintlan uel monemiltiz yuan inic quinpiaz yn maceualtin yn tecpantlaca». («Y el pájaro de quetzal y los cinco piedras verdes que los guarde mi hijo don Diego porque son atavíos reales. Le ruego mucho, por nuestro señor Dios, al tlatoani que no burle de su madre y todos mis hijos y mis hermanos menores y mis sobrinos y todos los magnificos señores [miembros del cabildo?], que los respete mucho y que viva bien entre los oficiales de calpolli y que guarde los plebeyos y la gente de techan» (VBO II: 191).
} 
hispánico. Sitúa la herencia de los atributos del mando en el contexto más amplio del legado de autoridad, dándole instrucciones de mando a su hijo y tal vez aludiendo al concepto del poder que parece enteramente tradicional. Además, en otra parte de su testamento, don Miguel utiliza la antigua metáfora referente al poder in petlatl in icpalli, «la estera, el trono», en relación a lo que pertenece al tecpan (VBO II: 191). Por ello, da la impresión de tratarse de un heredero consciente de sus antecesores prehispánicos, quien no sólo emplea correctamente el lenguaje de la realeza, sino que también guarda y reconoce el valor y significado de las antiguas insignias de rango.

Según los testamentos de los cuales disponemos, varios gobernantes y nobles de la segunda mitad del siglo XVI poseían también mantas tilmatli decoradas con plumas según la costumbre prehispánica ${ }^{10}$, plumería (mihuitl $)^{11}$, abanicos de plumas de quetzal quetzalehecacehuaztli ${ }^{12}$, brazaletes macuextli ${ }^{13}$, piedras cargadas de valor simbólico como chalchihuites y turquesas ${ }^{14}$, así como plumas de quetzal ${ }^{15}$, objetos que se encuentran en su totalidad asociados con la nobleza anterior a la conquista. Como rasgo muy importante se debe señalar que los dueños de los objetos antiguos o manufacturados según la tradición prehispánica empleaban la propia terminología referente a los objetos precoloniales.

Aunque con el tiempo decae la vigencia de esta tradición, varios testimonios de la supervivencia de antiguos objetos del rango y de la propia terminología asociada a ellos se manifiestan también en el siglo XVII. En el testamento del señor de la cabecera de Tepetenchi, de la ciudad de Xochimilco del año 1650, don Martín Cerón de Alvarado (VBO III: 235-252) se menciona ce chimalli cuextecatl, lo que parece ser el típico traje de origen prehispánico, el traje huasteco (cuextecatl) con su escudo. Este atuendo gozaba de gran popularidad antes de la conquista y se fabricaba en varios colores, siendo a veces decorado con oro y plumas preciosas. Es quizás significativo que don Martín se intitula a si mismo tlatoani y en su testamento pasa su señorío, que llama in tlatocayotl in cacicazgo, a su hijo don Diego Juarez que ya desempañaba el papel del gobernador.

10 p. ej. Testamento de Martín Lázaro Pantecatl, del barrio de Moyotlan, año 1551 (VBO II, 91), Testamento de María Xocoyotl, del barrio de Tepetenchi Tlalnepantla, ciudad de Xochimilco, año 1569 (VBO II, 153), Testamento de Francisco Xochpanecatl, del barrio Apanohaguayan, de la parte de Santa María Asumpción, ciudad de México, año 1576 (VBO II, 177, 179).

11 Testamento de don Francisco Verdugo Quetzalmamalictzin, gobernador de San Juan Teotihuacan, año 1563 (VBO II, 139).

12 Testamento de Ana Tiacapan, del barrio de Tepetenchi Tlalnepantla, ciudad de Xuchimilco, año 1566 (VBO II, 147).

13 Testamento de María Xocoyotl, del barrio de Tepetenchi Tlalnepantla, ciudad de Xochimilco, año 1569 (VBO II, 153).

14 P. ej. Testamento de don Miguel Alexandrino, gobernador de Tullantzinco, año 1577 (VBO II, 197), Testamento de Juana Francisca, del barrio de San Sebastián, de la parte de Tzaqualco, ciudad de México, año 1576 (II, 175), Testamento de doña Ana de Santa Bárbara, cacica principal de Santo Domingo Tepexi de la Seda, 1621 (VBO III, 119), Testamento de doña Ana de Guzmán, principal de la cabecera de Olac, Xochimilco, 1577 (VBO II, 211, 213), testamento de Juan Rafael Tlacochcalcatl, 1581, Culhuacan (TC, fol. 67v), Testamento de Mariana, viuda de Juan Rafael Tlacochcalcatl, 1581, Culhuacan (TC, fol. 64v), documento relativo al estado de Simón Moxixicoa, 1581, Culhuacan (TC, fol. 72r), anotaciones en nahuatl (TC, fols. 48r).

15 E.g. los indígenas conservaban también plumas ricas, como las de quetzal (VBO II, 323). 
En su testamento, doña María Xacoba, del pueblo de San Bartolomé Actopantonco, año 1673, enumera mantas descritas como «tlatocatocatilmanti» (probablemente tlatocatilmatli, «mantas de los señores») que incluyen las quauhtilmatli y ocelotilmatli - mantas con los diseños de águila y jaguar respectivamente (VBO III: 287), importantes objetos de rango en la época prehispánica. Los nombres de estas mantas se pueden trazar en las fuentes nahuas del siglo XVI -los Primeros Memoriales y Códice Florentino de Sahagún- en las listas de vestimentas más prestigiosas de la nobleza. También doña Petronila de Turcio de Amaquemecan, en su testamento del año 1625 , concede a sus herederos mantas referidas con el antiguo término de tilmatli, es más, son azules y labradas (texotlamacho, tetlamacho; VBO III: 165) de acuerdo con una larga tradición de estos prestigiosos vestidos.

Es difícil decir hasta qué punto estos objetos prestigiosos (y frecuentemente simbólicos) siguieron siendo empleados en la realidad diaria y en los contextos en las cuales se presentaban los miembros de la nobleza cumpliendo, por ejemplo, sus funciones municipales. Sin duda, el contexto principal mencionado por las fuentes disponibles en el cual sobrevivió el uso de los objetos del rango prehispánicos eran las fiestas y ceremonias, tanto religiosas, como seculares. Esta costumbre se remonta a las primeras décadas después de la conquista, manifestándose por ejemplo en las espléndidas fiestas reales celebradas en las colonias españolas con el propósito de reconocer un nuevo rey por los vasallos locales. Quizás la mejor ilustración de este tipo de fiestas aparece en el Códice de Tlatelolco que registra la jura al nuevo rey Felipe II celebrada en 1557 (Valle 1998). La probable actuación de los gobernantes indígenas de Tlatelolco, Tenochtitlan, Tlacopan y Tetzcoco con el traje prehispánico viene dada por el modo de su representación conforme a las convenciones precolombinas. También los danzantes visten trajes prestigiosos de jaguares y águilas, llevando en sus manos atributos prehispánicos como abanicos y flores. Lo que llama la atención es que esta vestimenta la llevan encima de los vestidos europeos, como camisas, jubones y pantalones, lo que confirma que es una representación bastante realista ${ }^{16}$.

Estas fiestas continuaron en los siglos XVII y XVIII ganando en refinamiento, sofisticación y exuberancia de los trajes y decoraciones, incluyendo atuendos militares en el estilo prehispánico vestidos por los indígenas que participaban en combates fingidos. En estas ocasiones los líderes indígenas llevaban ropaje e insignias precoloniales para manifestar su distinción, identidad histórica y estatus prestigioso (Curcio 2004: 41, 49-52). El uso de insignias y trajes de tradición prehispánica en los siglos posteriores lo confirman también varias pinturas, que parecen ser representaciones fieles de eventos contemporáneos, como el «Traslado de la imagen de la Virgen de Guadalupe a la primera ermita y presentación del primer milagro» del año $1653^{17}$. Los detalles de la pintura permiten identificar elementos de indumentaria llevada por los participantes de las celebraciones, como la trenzadera quetzallapiloni, el maxtlatl

16 Lo mismo ocurría en las fiestas reales en el Peru colonial, que también eran una oportunidad para manifestar los objetos del rango tradicionales (Espinoza 1995: 85-88).

17 Pinceles de la Historia. El origen del reino de la Nueva España, 1680-1750. Museo Nacional de Arte, Universidad Nacional Autónoma de México, Instituto de Investigaciones Estéticas, CONACULTA - INBA, México 1999, fig.74. 
o taparrabo con diseño de xicacoliuhqui, la insignia de bandera o pamitl, abanicos o trajes de jaguar.

Precisamente en estos contextos, relacionados con las festividades, aparecen varios términos prehispánicos asociados a las insignias de rango en las fuentes nahuas. Una muestra bastante ilustrativa procede de los Anales de Juan Bautista. Por ejemplo, con motivo de la llegada del virrey Gastón de Peralta se mencionan varios tipos de escudos, algunos de los cuales se pueden identificar con tipos de escudos prehispánicos, como el cuextecatl (fol. 1r). Las más frecuentes en el contexto festivo son las insignias, tanto trajes enteros como divisas. Así, durante la fiesta de San Francisco (fol. 6v) los amanalca se presentaron con tlamamalli tlachicomitl (la carga en la forma de un cántaro), sin duda un objeto relacionado con la divisa conocida como ocelotlachicomitl (divisa del cántaro de ocelotl) mencionada en el Códice Florentino como insignia de gobernantes y nobles (FC VIII: 35 ). Entre otros ejemplos de la terminología antigua que hacen referencia a los atuendos de origen prehispánico, aparecen insignias de Xipe (yopichimalli, yopihuehuetl), una mariposa de estrellas (citlalpapalotl), los trajes de danzantes en la forma de ocelotl, coyotl, cuitlachtli, aztatzontli (insignia de plumas de garza), tepozpamitl («bandera de metal» - quizás una combinación del elemento prehispánico con un material de origen europeo), tototenpilolli («pájaro colgado en el labio») - probablemente un bezote del tipo de quauhtentetl o quauhtenpilolli (Anales de Juan Bautista fols. 7v, 10v, 11r, 16r, 17v), todos ellos objetos enumerados en las fuentes primarias en referencia a los ornamentos prehispánicos. En un caso se menciona el «tlahuiztli casco» (fol. 58r), a lo mejor un equivalente del quacalalatli, o sea adorno de la cabeza en forma de casco (FC VIII: 74). Aparte del uso de las insignias precoloniales, los participantes de las fiestas se disfrazaban de miembros de los grupos prestigiosos antes de la conquista, como los guerreros quachichictli, sin duda vistiendo sus trajes típicos, que incluyeron el adorno de la cabeza llamado quachictzoncalli (Anales de Juan Bautista fol. 7r).

Lo que llama la atención no es sólo la mera supervivencia de los objetos y sus términos prehispánicos, sino también la de ciertos contextos y circunstancias de su empleo. Así, en una de las fiestas participaron los mercaderes quienes presentaron la prestigiosa insignia quetzalapanecayotl, que se colocó encima de las andas de San Francisco (Anales de Juan Bautista fol. 58r). Esta tradición del papel ritual de los pochteca y el uso de la divisa perteneciente a un género más amplio de quetzalpatzactli se remonta a los tiempos precoloniales y sobrevive a la conquista. Lo confirma también el Códice de Tlatelolco en la escena ya mencionada de la confirmación de la coronación de Felipe II que está acompañada por los quetzapatzactli. Estas insignias dan impresión de haberse convertido en los emblemas utilizados a la manera europea, pero a la vez parecen conservar el sentido prehispánico de los objetos prestigiosos de la nobleza exhibidos en las ceremonias públicas.

El empleo de los objetos precoloniales incluía también varias formas de transformación de su sentido original y del sincretismo, especialmente en los contextos religiosos. Una de las referencias más interesantes viene de la breve descripción Anales de Juan Bautista fol. 16r) de la fiesta de San Sebastián organizada en el año 1564. Durante la celebración tuvo lugar el ritual del palo volador patrocinado por don Pe- 
dro Tlacahuepan: según el relato, los atzaqualcas volaron disfrazados como «dos tlauhquechol, una mariposa y un xillanehuatl» ${ }^{18}$. Llama la atención el uso del traje de pluma del pájaro tlauhquecholli (espátula rosada) que en la época prehispánica era un atributo diagnóstico del dios Xipe Totec. Precisamente el tocado de estas plumas (así como otros ornamentos) llamado tlauhquecholtzontli lo llevaban los gobernantes mexicas como parte de su traje militar asociado con Xipe. Es posible que también el misterioso traje de xillanehuatl tenga alguna relación con este dios patrón del desollamiento: la palabra ehuatl puede referirse a parte del traje de guerrero, pero también, en su sentido primario, a la piel o traje de piel, mientras que xillantli significa vientre o costado, lo que resultaría en «piel de vientre» o «piel de costado». Antes de la conquista, las formas del sacrificio a Xipe incluían el flechamiento ritual y la muerte gladiatoria. ¿Tendría entonces que ver con una consciente alusión a este dios durante la fiesta de San Sebastián quien también murió flechado? ¿Sería un ejemplo de la supervivencia del simbolismo religioso prehispánico extendido al culto de un santo cristiano? El empleo de atributos de Xipe en contextos coloniales lo confirma también fray Diego Durán, quien, al describir a los danzantes prehispánicos que llevaban yopitzontli, el tocado de este dios, dice que estas «cabelleras hoy en día las usan. Y de todas las diferencias de los dioses que tenían, porque cada dios tenía una diferencia de cabellera, y ésas [usan] hoy en día, en los areitos» (Durán 1984, II: 277).

Los testimonios del uso de los objetos de origen prehispánico en los contextos festivos se encuentran también en los testamentos de la nobleza. El ya mencionado gobernador de San Francisco Tlahuililpan, don Pedro de San Francisco Tlaquixtecatl, en el año 1586, deja la antigua divisa quetzallamamalli a los nobles de su pueblo para que la usen en las danzas en días festivos ${ }^{19}$. Don Juan Jiménez, noble y ex-gobernador de Cuernavaca, en 1579 otorga a su esposa doña Bárbara tres escudos pequeños que sirven en los bailes («chimaltotontin nehtotiloni»), tambores tradicionales (teponazt$l i$, huehuetl, tlalpan huehuetl) y cuatro tocados de plumas (ihuitzoncalli), probablemente para el mismo fin. Don Juan poseía también una indumentaria española así como un caballo, freno, silla de montar, y mesas y ocho sillas españolas (Haskett 1985: 669).

Otro representante de la nobleza indígena, el gobernante de Yanhuitlan en las tierras mixtecas, don Gabriel de Guzmán, en su testamento del año 1591 declara que tiene en su poder «dos joyas que son dos cascabeles de oro para bailar, de la comunidad de Achiutla, en prenda de los cuarenta y cinco pesos y dos tomines que me deben» (VBO I: 150). Achiutla formó parte de su gobernación a través de su matrimonio con doña Isabel de Rojas, de manera que don Gabriel controlaba el patrimonio de su esposa también después de que esta falleció (Terraciano 2001: 175). Además, vale la pena añadir que sus posesiones incluyen numerosas joyas que reflejan la confluencia de las dos tradiciones, pues algunas pertenecen a las obras de artesanía e iconografía

\footnotetext{
18 «Axcan jueves a 20 de henero de 1564 a[ñ]os yquac ylhuitzin quiz in Sant Sebastia[n] auh yquac quauhpatla[n]que yn aztaqualca yn ipa[n] quauhpatla[n]que o[n]tetl tlauhquechol ce[n]tetl papalotl ce[n]tetl xillanehuatl auh in quahuitl yquauh in do[n] $\mathrm{P}[\mathrm{edr}] \mathrm{o}$ Tlacahuepa[n] ytlacohual yn itech quauhpatla[n]que.»

19 «Auh centetl quetzallamamalli yntech nicpouhtiuh yn pipilti yc macehuazque yn iquac mitotizque yn iquac ilhuitl quiztiuh»
} 
prehispánica mientras que otras, como imágenes de Cristo, Santa María o Santiago, forman parte del repertorio de objetos religiosos cristianos. En el primer grupo encontramos, por ejemplo, «una joya de oro grande que tiene doce cascabeles con figura de águila», o «un caimán con diez cascabeles de oro y unos chalchihuites». Estos objetos aludían a importantes símbolos del rango indígena y tenían los significados enraizados en la ideología y creencias precoloniales. No obstante, queda abierta la cuestión referida de hasta qué punto el gobernante educado por los dominicos, que era un cristiano ejemplar (Terraciano 2001: 280-281), mantenía el recuerdo de sus significados.

Según confirman los testamentos, la costumbre de usar los trajes e insignias prehispánicas en las festividades continúa en el período colonial tardío. Es de interés que el trasunto español hecho en el año 1686 del testamento del ya mencionado, don Martín Cerón de Alvarado (gobernante de Tepetenchi en la ciudad de Xochimilco) describe su traje guerrero de cuextecatl como «una figura que llaman quistecal que sacan en sus bailes», lo que implica que tuvo que ser una costumbre bastante difundida ${ }^{20}$.

Los contextos del empleo de la terminología indígena asociada al poder y rango sufrieron varios cambios, más o menos profundos, en la realidad de la Nueva España. Sin embargo, en varios casos las líneas de la supervivencia son bastante sorprendentes, especialmente si tomamos en cuenta varias modificaciones del sentido y los ajustes a un nuevo sistema político y administrativo. En el caso de los símbolos materiales de rango asociados con la nobleza, parece sorprendente el alcance de objetos identificados con sus correctos términos prehispánicos que conservaban o mencionaban las elites y comunidades coloniales, utilizándolos en ciertas ocasiones y legándolos a los sucesores. Como es de suponer, la continuación de esta terminología conlleva la supervivencia de ciertos conceptos importantes aunque fueran adaptados y asimilados a los oficios, cargos e ideas de origen español.

Aunque la memoria histórica relacionada con la pervivencia de las insignias antiguas en los contextos festivos pudo haber sido bastante superficial -es posible que en muchos casos se tratase tan sólo de una convención «teatral» vinculada con el pasado prehispánico- vale la pena resaltar que este contexto del uso de los trajes y varios atributos está de pleno acuerdo con su exuberante empleo en la época prehispánica en rituales y celebraciones. Si bien es difícil recuperar las posibles ideas y conceptos ligados a los símbolos del rango de su mera presencia en las fiestas coloniales, algunos datos de los testamentos parecen bastante sugerentes. Al menos en el caso de algunos individuos importantes, los propios descendientes de los gobernantes prehispánicos, se puede observar una continuada asociación de las insignias con el otorgamiento y herencia de poder así como con un estatus arraigado en la tradición prehispánica. Sin duda, tal y como el título de cacique y gobernador reflejaba la coexistencia de las bases prehispánica y española del poder indígena en la Nueva España del siglo XVI,

\footnotetext{
20 «ome pancocolli nahui maçohualoni ce chimalli cuextecatl» lo que se comenta en la traducción hecha en 1686 de la manera siguiente: «dos abanicos de pluma y un broquel de pluma y una figura que llaman quistecal que sacan en sus bailes» (VBO III: 242-243).
} 
la nobleza gozaba de lo atractivo de la vestimenta española, pero a la vez guardaba la memoria de sus raíces y legitimaba su posición con atributos heredados.

\begin{abstract}
Abreviaturas
CF - Códice Florentino, véase: SAHAGún, Bernardino de, 1950-1982.

TC - The Testaments of Culhuacan, véase: Cline, S.L, y Miguel León Portilla, 1984.

VBO - Vidas y bienes olvidados, véase: RoJas RABIELA, Teresa et al., 1999-2000.
\end{abstract}

\title{
Referencias bibliográficas
}

Anales de Juan Bautista - véase: Reyes García, Luis, 2001.

Anales de Tecamachalco - véase: Celestino Solís, Eustaquio, y Luis Reyes García, 1992.

Anderson, Arthur, Frances Berdan y James LockHART (eds.)

1976 Beyond the Codices. The Nahua View of Colonial Mexico. Los Angeles: UCLA Latin American Center.

Celestino Solís, Eustaquio y Luis Reyes García

1992 Anales de Tecamachalco 1398-1590. México: Fondo de Cultura Económica.

Cline, S.L. y Miguel León Portilla (eds.)

1984 The Testaments of Culhuacan. Los Angeles: UCLA Latin American Center Publications, University of California.

CuRCio-Nagy, Linda A.

2004 The Great Festivals of Colonial Mexico City. Performing Power and Identity. Albuquerque: University of New Mexico Press.

DuRÁn, fray Diego,

1984 Historia de las Indias de la Nueva España e islas de la tierra firme. México: Editorial Porrúa.

Espinoza, Carlos

1995 «Colonial Visions. Drama, Art and Legitimation in Peru and Ecuador», en Native Artists and Patrons in Colonial Latin America. Phoebus. A Journal of Art History, E. Umberger y T. Cummins, eds., Vol. 7, pp. 84-105. Tempe: Arizona State University.

HASKETT, Robert

1985 A Social History of Indian Town Government in the Colonial Cuernavaca Jurisdiction, Mexico. Tesis Doctoral. Ann Arbor: University Microfilms International.

1991 Indigenous Rulers. An Ethnohistory of Town Government in Colonial Cuernavaca. Albuquerque: University of New Mexico Press. 
Horn, Rebecca

1997 Postconquest Coyoacan. Nahua-Spanish Relations in Central Mexico, 1519-1650. Stanford: Stanford University Press.

KuBLER, George

1964 «On the Colonial Extinction of the Motifs of Pre-Columbian Art», en Essays in Pre-Columbian Art and Archaeology, S. Lothrop et al., eds., pp. 14-34. Cambridge: Harvard University Press.

LOCKHART, James

1992 The Nahuas After the Conquest. A Social and Cultural History of the Indians of Central Mexico, Sixteenth Through Eighteenth Centuries. Stanford: Stanford University Press.

s.f. Document 1. «Testament of don Julián de la Rosa», en Beyond the Codices. The Nahua View of Colonial Mexico (nueva edición), Early Nahuatl Library, www. whp.uoregon.edu, en proceso de la publicación.

Molina, Alonso de

2001 Vocabulario en Lengua Castellana y Mexicana y Mexicana y Castellana. México: Editorial Porrúa.

OLKo, Justyna

2005 Turquoise Diadems and Staffs of Office. Elite Costume and Insignia of Power in Aztec and Early Colonial Mexico. Varsovia: Sociedad Polaca de Estudios Latinoamericanos - Centro de Estudios sobre la Tradición Clásica, Universidad de Varsovia.

2008 «Convenciones y estrategias en la iconografía del rango de la nobleza indígena del centro de México en el siglo XVI». Revista Española de Antropología Americana vol. 38 (2): 207-240.

REYEs GARCíA, Luis

1988 Cuauhtinchan del siglo XII al XVI. Formación y desarollo histórico de un señorio prehispánico. México: Fondo de Cultura Económica.

2001 ¿Cómo te confundes? ¿Acaso no somos conquistados? Anales de Juan Bautista. México: Biblioteca Lorenzo Boturini Insigne y Nacional Basílica de Guadalupe y CIESAS.

RoJAs, Jose Luis de

2010 Cambiar para que yo no cambie. La nobleza indígena en la Nueva España. Buenos Aires: S.B.

Rojas Rabiela, Teresa, Elsa Leticia Rea LóPez y Constantino Medina Luna

1999-2000 Vidas y bienes olvidados. Testamentos indigenas novohispanos, vols. 2 у 3 , México: CIESAS.

SAHAGUN, Bernardino de

1950-82 Florentine Codex. General History of the Things of New Spain, 12 vols., edición y traducción de Arthur J. O. Anderson y Charles Dibble. Santa Fe: The School of American Research - University of Utah.

SulLivan, Thelma

1987 Documentos tlaxcaltecas del siglo XVI en lengua náhuatl, México: Universidad Nacional Autónoma de México. 
TERRACIANO, Kevin

2001 The Mixtecs of Colonial Oaxaca. Stanford: Stanford University Press.

Tezozomoc, Francisco Alvarado

2001 Crónica mexicana. Madrid: Editorial Dastin.

Valle Pérez, Perla

1998 «La sección VIII del Códice de Tlatelolco. Una nueva propuesta de lectura», en De tlacuilos y escribanos. Estudios sobre documentos indigenas coloniales del centro de México, Xavier Noguez y Stephanie Wood, eds, pp. 33-47. Zamora: El Colegio de Michoacan. 